\title{
ANTERIOR ETHMOIDAL NERVE BLOCK IN PREVENTION OF POST-OPERATIVE AGITATION FOLLOWING NASAL SURGERIES WITH NASAL PACKS UNDER GENERAL ANESTHESIA: AN EXPERIMENTAL STUDY
}

Anup Acharya, ${ }^{1}$ Nil Raj Sharma, ${ }^{2}$ Bandana Pokharel, ${ }^{3}$ Shiva Bhushan Pandit, ${ }^{4}$ Suman Badtaula ${ }^{4}$

\begin{abstract}
\section{INTRODUCTION}

Postoperative agitation or emergence agitation during recovery from anesthesia is an important complication of General Anesthesia (GA) especially in otolaryngological surgeries, and nasal surgery in particular. It is potentially harmful to the patients resulting in fall from the operation table, self-extubation, self-removal of nasal pack, hemorrhage etc. Several methods and medications have been tried to reduce it. We studied the effect of anterior ethmoidal nerve block for reducing post-operative agitation for nasal surgeries with nasal packs as it falls in the same operative field.
\end{abstract}

\section{MATERIAL AND METHODS}

A total of 100 participants undergoing nasal surgeries with nasal pack under GA in the Department of Otolaryngology, Lumbini Medical College, Palpa, Nepal, were randomized into cases and controls by block randomization. The study was done from June 2018 till February 2020. Anterior ethmoidal nerve was blocked with bupivacaine injection at the end of surgery in cases. Controls were injected with normal saline. Post-operative agitation was studied with Riker SedationAgitation Scale (SAS) and was compared between the two groups.

\section{RESULTS}

There were 50 participants in each group. Emergence agitation in cases and controls at extubation, 30 minutes postextubation and the next morning was present in $32 \%$ and $52 \%, 4 \%$ and $18 \%$, and 0 and $2 \%$ respectively. SAS score rapidly decreased in 30 minutes after extubation in controls but was still significantly higher than that of cases.

\section{CONCLUSION}

Anterior ethmoidal nerve block was effective in reducing post-operative agitation significantly during emergence in nasal surgeries with nasal packs.

\section{KEYWORDS}

Anterior ethmoidal nerve block, Nasal pack, Post-operative agitation.

1. Department of ENT \& Head and Neck Surgery, Universal College of Medical Sciences, Bhairahawa, Nepal

2. Department of Anesthesiology and Critical Care, Lumbini Medical College, Palpa, Nepal

3. Department of Nursing, Lumbini Medical College, Palpa, Nepal

4. Department of ENT \& Head and Neck Surgery, Lumbini Medical College, Palpa, Nepal

DOI: http//doi.org/10.3126/jucms.v8i02.34091

For Correspondence

Dr. Anup Acharya

Department of ENT \& Head and Neck Surgery

Universal College of Medical Sciences

Bhairahawa, Nepal

Email:anupent@gmail.com 


\section{INTRODUCTION}

Postoperative agitation during emergence after a surgery is an important complication of General Anesthesia (GA). Otolaryngological surgery is considered as a risk factor for development of emergence agitation. ${ }^{1}$ Nasal packs following nasal surgery amplifies this risk. ${ }^{2}$ Postoperative agitation is potentially harmful to the patients and the operative room staff. A patient may sustain physical injury in form of bruises or fall from the operation table, self-extubation, increased pain, hemorrhage, and removal of catheters, nasal packs, or oxygen masks. ${ }^{3}$ This may lead to further complications such as desaturation and aspiration of blood. There have been occasions when the agitated patient has caused injury to the operative room (OR) staff. We have an experience of an operative room staff sustaining fractured nasal bones by an agitated patient recovering from general anesthesia.

There are very few articles about reducing post-operative agitation of patients, especially those undergoing nasal surgeries with nasal packs. Anterior ethmoidal nerve block is one of them and it falls in the same operative field. The objective of this study was to observe the occurrence of postoperative agitation in patients undergoing nasal surgery with nasal pack and study the effect of anterior ethmoidal nerve block in reducing the agitation.

\section{MATERIAL AND METHODS}

This was an experimental study conducted in Department of Otolaryngology Head and Neck Surgery, Lumbini Medical College and Teaching Hospital, Palpa, Nepal. The study was done from June 2018 till February 2020. It was approved by the Institutional Review Committee of the Hospital and was registered in the clinical "trial registry" (https://clinicaltrials. gov/show/NCT 03427502).

All patients undergoing nasal surgery with nasal packs under general anesthesia were included irrespective of age and gender. Those who did not consent to the study or had history of allergy to lignocaine or bupivacaine were excluded from the study. Participants were randomized into two groups according to randomization table; cases and controls. Randomization was done by block randomization, with blocks of four. The blocks were generated randomly by an author, who was not directly involved in treatment of the patients. A study found that the occurrence of post-operative agitation in patients undergoing ENT surgery under general anesthesia was $55.4 \%{ }^{2}$ We expect to reduce this by at least $50 \%$ by blocking anterior ethmoidal nerve, thus reducing the occurrence to $27.7 \%$. With alpha error of 0.05 , beta error of 0.2 , ratio of participants in two group of 1 , minimum sample size was calculated to be 49 in each group.

\section{Surgical technique}

All the patients were anesthetized by the same anesthesia team in a similar way. At the end of the nasal surgery, before nasal packing, scrub nurse prepared a solution of anesthesia or placebo according to the randomization table. Solution of anesthesia consisted of $10 \mathrm{ml}$ of $0.5 \%$ bupivacaine with $1: 2,00,000$ adrenaline. For children less than 12 years of age, a solution of $0.25 \%$ bupivacaine with $1: 2,00,000$ adrenaline was used. Placebo consists of $10 \mathrm{ml}$ of normal saline. Both the surgeon and anesthetists were blinded. External nasal branch of anterior ethmoidal nerve was blocked on each side through an inter-cartilaginous injection into the dorsum of the nose. Solution was dumped along the dorsum forming a longitudinal swelling in the dorsum of the nose. About $0.75 \mathrm{ml}$ of solution was dumped in adults on each side. Internal nasal nerve was blocked in septum and in lateral wall of nose. One injection was given in the upper anterior part of nasal septum mucosa depositing one $\mathrm{ml}$ of solution on each side. Three injections were given on each side on the lateral nasal wall. First injection was given just antero-superior to the attachment of middle turbinate to fronto-nasal process (Axilla of middle turbinate) depositing about one $\mathrm{ml}$ of solution. Second injection was given at the anterior end of middle turbinate depositing about $0.5 \mathrm{ml}$ of solution. Third injection was given at the medial surface of middle turbinate depositing about 0.5 $\mathrm{ml}$ of solution. Thus, about $7.5 \mathrm{ml}$ was injected in total amounting to $37.5 \mathrm{mg}$ of bupivacaine. ${ }^{4,5}$ Withdrawal of injection was done prior to deposition of solution every time to ensure that the solution was not deposited directly into a blood vessel. For the control group, similar injections of normal saline was injected.

Agitation score was recorded using Riker Sedation-Agitation Scale (SAS) according to Table 1 by a surgeon or an anesthetist who was blinded to the study. ${ }^{6,7}$ First scoring was done after extubation on the operating table before patient was shifted out of the operating room. Second scoring was done in the recovery room after 30 minutes of the first score. Third scoring was done the next morning in the rounds. A participant was tagged as having agitation if the score was 5 or higher.

\section{Table 1. Riker Sedation-Agitation Scale (SAS) scoring}

\begin{tabular}{|c|c|c|}
\hline Score & Term & Description \\
\hline 7 & Dangerous Agitation & $\begin{array}{l}\text { Pulling ET tube, trying to remove catheters, climbing over } \\
\text { bedrail, striking at staff, thrashing side to side }\end{array}$ \\
\hline 6 & Very Agitated & $\begin{array}{l}\text { Requiring restraint and frequent verbal reminding of limits, } \\
\text { biting ETT }\end{array}$ \\
\hline 5 & Agitated & Anxious or physically agitated, calms to verbal instructions \\
\hline 4 & Calm and Cooperative & Calm, easy arousable, follows commands \\
\hline 3 & Sedated & $\begin{array}{l}\text { Difficult to arouse but awakens to verbal stimuli or gentle } \\
\text { staking, follows simple commands but drifts off again }\end{array}$ \\
\hline 2 & Very Sedated & $\begin{array}{l}\text { Arouses to physical stimuli but does not communicate or } \\
\text { follow commands, may move spontaneously }\end{array}$ \\
\hline 1 & Unarousable & $\begin{array}{l}\text { Minimal or no response to noxious stimuli, does not } \\
\text { communicate or follow commands }\end{array}$ \\
\hline
\end{tabular}

Data was entered in Microsoft Excel 2008 and then important to Statistical Package for the Social Sciences (SPSS) version 16. Presence of emergence agitation in two groups was compared with Chi-square test. SAS scores were compared by Mann-Whitney U test. P value less than 0.05 was considered statistically significant. 


\section{RESULTS}

There were a total of 100 subjects divided equally into Case and Control groups, thus there were 50 subjects in each group. There were $58(58 \%)$ males and $42(42 \%)$ females. Mean age of the participants was 36.03 years $(\mathrm{SD}=13.43)$. Diagnosis and procedure carried out in the subjects are presented in Table 2 .

Table 2. Diagnosis and procedure carried out in the participants

\begin{tabular}{cllc}
\hline S.No & Diagnosis & Procedure & n (\%) \\
\hline 1 & AC Polyp & Endoscopic removal & $5(5 \%)$ \\
2 & DNS & Septoplasty & $16(16 \%)$ \\
3 & CRS & FESS & $62(62 \%)$ \\
4 & CRS + DNS & FESS + Septoplasty & $14(14 \%)$ \\
5 & Inverted Papilloma & Endoscopic infero-medial maxillectomy & $3(3 \%)$ \\
\hline Total & & & $100(100 \%)$ \\
\hline
\end{tabular}

AC AntroChoanal; DNS Deviated Nasal Septum; CRS Chronic Rhino Sinusitis; FESS Functional Endoscopic Sinus Surgery

Prevalence of post-operative agitation in groups across various time period is given in Table 3. It shows that the agitation was significantly higher in controls at the time of extubation and at 30 minutes post-extubation and was comparable the next morning.

Table 3. Post-operative agitation across various time period in cases and controls

\begin{tabular}{llccc}
\hline Time period & Study group & \multicolumn{2}{c}{ Post-operative agitaion } & Stats \\
& & Present & Absent & \\
\hline \multirow{2}{*}{$\begin{array}{llcc}\text { At the time of } \\
\text { extubation }\end{array}$} & Case & $16(32 \%)$ & $34(68 \%)$ & $\mathrm{X}^{2}=4.1, \mathrm{df}=1$, \\
At 30 minutes & Control & $26(52 \%)$ & $24(48 \%)$ & $\mathrm{p}=0.043$ \\
post extubation & Control & $2(4 \%)$ & $48(96 \%)$ & $\mathrm{X}^{2}=5, \mathrm{df}=1$, \\
Next morning & Case & 0 & $50(100 \%)$ & $\mathrm{P}=1$ (Fisher's \\
& control & $1(2 \%)$ & $49(98 \%)$ & exact test) \\
\hline
\end{tabular}

The trend of mean SAS score across time in both groups is shown in Figure 1. It shows that the mean SAS score in cases at the time of extubation was much higher $(\mathrm{U}=1896, \mathrm{p}<0.001)$ which rapidly decreased over next 30 minutes but was still higher than the controls with a small but significant difference $(\mathrm{U}=1506, \mathrm{p}=0.044)$. The score was comparable the next day $(\mathrm{U}=1347, \mathrm{p}=0.2)$.

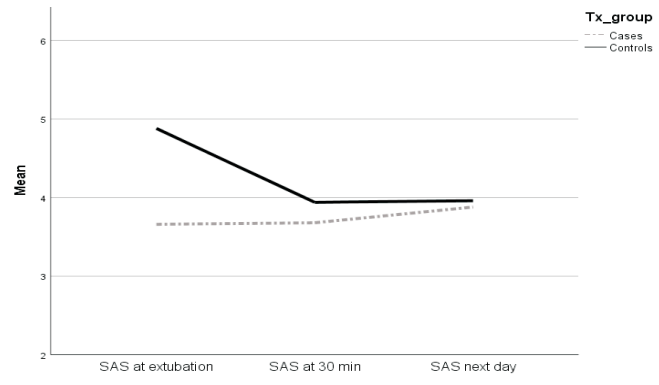

Figure 1.SAS score across time in both groups

\section{DISCUSSION}

Our objective was to observe the occurrence of post-operative agitation in patients undergoing nasal surgery with nasal pack and compare it between those with anterior ethmoidal nerve block (cases) and those without the block (controls). We found that the agitation was much lower in those with nerve block.

Post-operative agitation during emergence from anesthesia is a common phenomenon, especially in patients undergoing nasal surgeries in which it can be as high as $68 \%$, though it is present in surgery of other body parts with lower prevalence. ${ }^{2,3,8}$ It is present only in about $9.8 \%$ of patients undergoing urologic surgery and $6.4 \%$ in breast surgery. ${ }^{8}$ Nose of the patients are generally packed to prevent post-operative bleeding and dislodgement of nasal flaps if created during surgery. The exact mechanism of development of agitation in patients with nasal surgery is unknown. Some believe that the presence of nasal pack itself triggers agitation while other argues that the sensation of pressure in the nasal cavity due to nasal pack may trigger the phenomenon. ${ }^{2,8}$ Sensation of pressure in the nasal cavity can be abolished to a great extent by anesthetizing the branches of anterior ethmoidal nerve. ${ }^{4}$ In this study, we blocked anterior ethmoidal nerve by local infiltration of bupivacaine.

In our study, post-operative agitation was present in $32 \%$ of the cases and $52 \%$ of controls at the time of extubation. This difference was statistically significant which states that anterior ethmoidal nerve block was effective in reducing postoperative agitation. We do not know how exactly the blockage of the nerve reduced agitation; it might have reduced pain or sensation of nose blockade or sensation of presence of nasal pack or something else. A similar study found agitation in $24 \%$ versus $48 \%$ in cases and controls respectively which was comparable to the findings of our study. ${ }^{9}$ Studies have found various other methods for reducing emergence agitation including nerve blocks. ${ }^{10}$ Infraorbital nerve block was effective in doing so in children undergoing cleft lip surgery under general anesthesia. ${ }^{11}$ Another study found ketamine at sub-anesthetic dose to significantly reduce emergence anesthesia for patients undergoing rhinoplasty, $54.3 \%$ versus $8.6 \%$. ${ }^{12}$ Similarly, dexmedetomidine was found to be effective in reducing emergence for a variable time period after extubationin various types of surgeries under general anesthesia. $^{13-15}$

The agitation score decreased rapidly in controls over 30 minutes from the time of extubation but was still significantly higher than the cases in whom it was almost stationary for the duration. This may be due to wearing off of the effects of anesthetic agents during recovery. The agitation effect was already low in cases due to ethmoidal block which remained almost the same.

It was a single center study which included few types of nasal surgeries. Multi-centric study with involvement of various geographic regions, races, socioeconomic conditions, variety 
of nasal surgeries with a larger population would increase the validity of the study. Also, analysis of other factors by means of multi-variate analysis would provide new and more precise results. We would recommend the surgeons performing nasal surgeries with post-operative packing, under general anesthesia, to routine block the anterior ethmoidal nerve as it would take little extra effort and no additional cost but would significantly reduce emergence anesthesia and its complications. Further, the exact mechanism how the blockade of nerve reduces the agitation needs to be explored.

\section{CONCLUSION}

Prevalence of emergence agitation was high following nasal surgeries. Anterior ethmoidal nerve block at the end of surgery was effective in significantly reducing its prevalence in immediate post extubation period and after 30 minutes of extubation.

\section{REFERENCES}

1. Mizuno J, Nakata Y, Morita S, Arita H, Hanaoka K. Predisposing factors and prevention of emergence agitation. Masui. 2011 Apr;60(4):425-35

2. Yu D, Chai W, Sun X, Yao L. Emergence agitation in adults: risk factors in 2,000 patients. Can J Anesth Can Anesth. 2010 Sep $1 ; 57(9): 843-8$.

3. Kim H-C, Kim E, Jeon Y-T, Hwang J-W, Lim Y-J, Seo J-H, et al. Postanaesthetic emergence agitation in adult patients after general anaesthesia for urological surgery. J Int Med Res. 2015 Apr 1;43(2):226-35

4. Lal D, Gnagi SH. Nose Anesthesia: Overview, indications, contraindications. emedicine.medscape. 2017 May 12. [cited 2018 Jan 30]; Available from: https://emedicine.medscape. com/article/82679-overview

5. Seitchik MW. Anterior ethmoid nerve block for the treatment of nasal fractures. Plast Reconstr Surg. 1971 Aug;48(2):187.

6. Sessler CN, Gosnell MS, Grap MJ, Brophy GM, O'Neal PV, Keane KA, et al. The Richmond Agitation-Sedation Scale: validity and reliability in adult intensive care unit patients. Am J Respir Crit Care Med. 2002 Nov 15;166(10):1338-44.

7. Khan BA, Guzman O, Campbell NL, Walroth T, Tricker JL, Hui $\mathrm{SL}$, et al. Comparison and agreement between the Richmond Agitation-Sedation Scale and the Riker Sedation-Agitation Scale in evaluating patients' eligibility for delirium assessment in the ICU. Chest. $2012 \mathrm{Jul} ; 142(1): 48-54$

8. Kim H-J, Kim D-K, Kim H-Y, Kim J-K, Choi S-W. Risk factors of emergence agitation in adults undergoing general anesthesia for nasal surgery. Clin Exp Otorhinolaryngol. 2015 Mar;8(1) :46-51.

9. Ibrahim M, Elnabtity AM, Keera A. Efficacy of external nasal nerve block following nasal surgery. Anaesthesist. 2018 Mar 1;67(3):188-97.
10. Choi H, Jung SH, Hong JM, Joo YH, Kim Y, Hong SH. Effects of bilateral infraorbital and infratrochlear nerve block on emergence agitation after septorhinoplasty: A randomized controlled trial. J Clin Med. 2019 May 30;8(6).

11. Wang H, Liu G, Fu W, Li S. The effect of infraorbital nerve block on emergence agitation in children undergoing cleft lip surgery under general anesthesia with sevoflurane. Pediatr Anesth. 2015;25(9):906-10.

12. Demir CY, Yuzkat N. Prevention of emergence agitation with ketamine in rhinoplasty. Aesthetic Plast Surg. 2018 Jun 1;42 (3):847-53.

13. Boku A, Hanamoto H, Oyamaguchi A, Inoue M, Morimoto Y, Niwa H. Effectiveness of dexmedetomidine for emergence agitation in infants undergoing palatoplasty: A randomized controlled trial. Braz J Anesthesiol (Engl Ed). 2016 Jan $1 ; 66(1): 37-43$

14. Kim JA, Ahn HJ, Yang M, Lee SH, Jeong H, Seong BG. Intraoperative use of dexmedetomidine for the prevention of emergence agitation and postoperative delirium in thoracic surgery: A randomized-controlled trial. Can J Anesth Can Anesth. 2019Apr 1;66(4):371-9.

15. Hauber JA, Davis PJ, Bendel LP, Martyn SV, McCarthy DL, Evans $\mathrm{M}-\mathrm{C}$, et al. Dexmedetomidine as a rapid bolus for treatment and prophylactic prevention of emergence agitation in anesthetized children. Anesth Analg. 2015 Nov 1;121(5) :1308-15. 